DOI: $10.5216 /$ racs.v4.59089

\title{
Políticas de retomada de línguas indígenas em diferentes contextos epistêmicos
}

Maria do Socorro Pimentel da Silva ${ }^{1}$

\section{RESUMO}

As temáticas que compõem este artigo refletem os resultados das pesquisas realizadas para o projeto Impactos dos Usos das Línguas Indígenas na Formação de Professores Indígenas no Curso de Licenciatura Intercultural de Formação Superior de Professores Indígenas. Os resultados desse estudo estão contribuindo para a implementação de políticas de valorização dessas línguas na escola e seu fortalecimento nas comunidades indígenas. A partir dessas ideias, é possível propor mudanças pedagógicas, transformando a prática educativa bilíngue em uma ação efetiva para que o ensino consiga transpor as dimensões do espaço escolar, possibilitando uma articulação, tanto com a cosmovisão de cada povo indígena, quanto com as demandas contemporâneas interculturais.

PALAVRAS-CHAVE: Línguas indígenas. Formação de professores. Bilinguismo.

\section{Políticas Dèlèmyhỹde ixỹju mahâdu rỹira ixby tarybè rimykremy inatàhàmy tièmy myle}

\section{TURYBÈNABUTE}

Kama rybè kòraru artigo-ki kdoikre anoma ratxirèri pesquisa relere kuldu anoma projeto-kò relere Impactos dos Usos das Línguas Indígenas na Formação de professores Indígenas no Curso de Licenciatura Intercultural de Formação Superior de Professores Indígenas. Kiamy, kiatahè irbi iny riwitxòhènanyrèri ratyhydkỹkremy iny bdèdkỹnana roimyhỹre iny rybè boho boho tkyrtina-ki ixỹ kykymy tule ratyhydkỹrèri iny rikuhèrèri tabdèdkỹnana. Kawsè rakykyki tahè tkyrti bdèdkỹnana iny tkyrtina rawitxirakre, inatxi rybèna rakèrymy rarakre ihykysè rarakymy rarakre iwitxira witxira-kò, butumy rakèrymy rarakre, hàri bdèdkỹnana ixỹju kòtakòta rikèrymy rỹira rakèrylekè timykèkibo anoma wahè bdèkèry butu-kò kèryna

RYBÈNA KÒRARUKRE: Ixỹju rybè. Tkyrtidu mahãdu bdèkèryna. Inatximy rybèna.

\footnotetext{
${ }^{1}$ Doutora em Linguística Aplicada ao Ensino de Línguas pela Pontifícia Universidade Católica de São Paulo. Pós-doutorado em Linguística pela UNICAMP. Professora do Núcleo Takinahakỹ de Formação Superior Indígena (NTFSI) e da Pós-Graduação em Letras e Linguística/UFG. Goiânia, GO, Brasil. E-mail: smariapimentel@yahoo.com.br.
} 


\section{Políticas de reanudación de las lenguas indígenas en diferentes contextos epistémicos}

\section{RESÚMEN}

Las temáticas que componen este artículo reflejan los resultados de las investigaciones realizadas para el proyecto Impactos de los Usos de las Lenguas Indígenas en la Formación de Profesores Indígenas en el Curso de Licenciatura Intercultural de Formación Superior de Profesores Indígenas. Los resultados de este estudio están contribuyendo a la implementación de políticas de valorización de esas lenguas en la escuela y su fortalecimiento en las comunidades indígenas. A partir de esas ideas, es posible proponer cambios pedagógicos, transformando la práctica educativa bilingüe en una acción efectiva para que la enseñanza pueda transponer las dimensiones del espacio escolar, posibilitando una articulación, tanto con la cosmovisión de cada pueblo indígena, cuanto con las demandas contemporáneas intercultural.

PALABRAS-CLAVE: Lenguas indígenas. Formación de profesores. Bilinguismo.

\section{Apresentação}

As temáticas que compõem este artigo refletem os resultados das pesquisas realizadas entre os anos de 2012 a 2016 com o projeto ${ }^{2}$ Impactos dos Usos das Línguas Indígenas na Formação de Professores Indígenas no Curso de Licenciatura Intercultural de Formação Superior de Professores Indígenas da Universidade Federal de Goiás ${ }^{3}$. Os estudos foram realizados nas seguintes etapas do curso: (1) na Universidade Federal de Goiás (UFG), nos meses de janeiro a fevereiro e de julho a agosto. Nesse período, foram observadas as palestras que acontecem nas tardes de sábado, quando os alunos indígenas, a maioria de professores em suas comunidades, apresentam suas experiências pedagógicas e pesquisas dos projetos extraescolares ${ }^{4}$, uma linha de estudo e documentação de saberes tradicionais, em línguas maternas, em suas comunidades; (2) em estudos presenciais nas terras indígenas de abril a junho (primeiro semestre) e de setembro a novembro (segundo semestre); (3) nas escolas indígenas. Participaram do projeto, além desta autora e também coordenadora, os bolsistas, a mestranda Fernanda Cardoso da Cunha Gomes (Pós-Graduação em Letras e Linguística da

\footnotetext{
${ }^{2}$ Projeto financiado pelo Programa Observatório da Educação - CAPES (Coordenação de Aperfeiçoamento de Pessoal de Nível Superior).

${ }^{3} \mathrm{O}$ nome do curso mudou para Educação Intercultural de Formação Superior de Professor Indígena, denominação usada neste artigo.

${ }^{4}$ Projeto extraescolar é uma ação de pesquisa e documentação de saberes indígenas, tendo como línguas oficiais, as indígenas, dos respectivos povos representados pelos/as acadêmicos/as do Curso de Educação Intercultural da UFG.
}

Dossiê Práticas de bem viver: diálogos possíveis entre o Núcleo Takinahakỹ e Milpas Educativas 
UFG) e os indígenas Cipriano Timbira, Leonice Gavião, Marli Bandeira Krikati (Maranhão), Kawina Karajá, Klebson Awararawooi Tapirapé (Mato Grosso), José Kumrizdazê Xerente (Tocantins), todos alunos do Curso de Educação Intercultural da citada universidade.

Os pesquisadores desenvolveram esses trabalhos em suas comunidades. O tema selecionado por cada um foi contextualizado na documentação dos saberes especializados e no estudo da situação de usos das línguas indígenas entre gerações e nos espaços culturais. Os resultados dos estudos feitos pelos pesquisadores indígenas e também por mim com as comunidades Karajá mostram que as línguas indígenas faladas na região Araguaia-Tocantins, que abrange os estados do Tocantins, Goiás, Mato Grosso e Maranhão, estão perigosamente ameaçadas. Muitos dos espaços de usos especializados dessas línguas encontram-se, segundo os pesquisadores citados, em condições de retomada de saberes milenares e de ativação cultural. Os Karajá, os Xerente e os Tapirapé estão adotando políticas de criação para nomear realidades novas que surgem mediante a convivência intercultural em diferentes contextos de comunicação. Também faz parte da política de vitalidade das línguas indígenas a publicação dos saberes especializados para circular nas comunidades indígenas, entre gerações, nas escolas indígenas, e também como um meio de tornarem-se conhecidos pela sociedade não indígena.

Os resultados dessas pesquisas serviram também de base e motivação para que os estudiosos/estudiosas indígenas, professores/professoras em suas comunidades, desenvolvessem atividades de atualização cultural, priorizando: (1) o envolvimento da juventude em práticas culturais específicas; (2) a participação dos sábios na formação do/a pesquisador/a indígena; (3) o avivamento dos espaços epistêmicos adormecidos; (4) a revitalização das línguas maternas; (5) a valorização dos conhecimentos tradicionais; e (6) o letramento em línguas indígenas voltado para o fortalecimento da oralidade dos saberes milenares. Tudo isso fundamentado no paradigma de retomada de saberes indígenas ancestrais, conforme Pimentel da Silva (2017).

Considerar esses apontamentos significa pensar em planejamentos educacionais de valorização das línguas indígenas em diferentes modalidades e contextos, como o faz o curso da Educação Intercultural que promove o prestígio dessas línguas em várias ações pedagógicas, de pesquisa e extensão. Os resultados dessas ações e dos estudos feitos pelos pesquisadores indígenas contribuem para que estes conheçam mais dos seus próprios saberes. Pelo menos é isso que escuto nas reflexões feitas por esses estudiosos e estudiosas. Teijolori Karajá (2018), por exemplo, colocou no seu artigo Iny-ki Ijasò riòrarunyre-my ijyy (história 
do ritual de Ijasò), muitas reflexões sobre a retomada de saberes milenares de seu povo. São muitos os exemplos de retomada de práticas culturais ligadas à alimentação tradicional, ao cuidado com as plantas medicinais, com os remédios tradicionais, com a economia sustentável, cuidado com o território, com os rituais etc.

Os resultados desses estudos entre os indígenas despertam no corpo docente o entendimento de que a educação intercultural é uma composição de muitas partes, pontos de vistas, leituras de mundo, diversidade de saberes, lutas, disciplinarização dos saberes, e tendências neo-colonizadoras que impõe aos povos chamados de oprimidos a hegemonia política, econômica e cultural das elites. Além disso, ainda há os modos definidos de produções científicas, os modelos pedagógicos, metodológicos e os avaliativos etc.

As universidades, em quase todos os cursos, estão presas ao modelo de conhecimento disciplinar, fragmentário e hierárquico. Reflexões como essas permitem pensar outro modelo de escola, e de um ensino integrado ao modo de ser dos povos indígenas, de suas demandas e projetos. Isso só se faz na base da coteorização, ou seja, a de construir conhecimento levando em conta diversos marcos epistêmicos. Em outras palavras, a coteorização é um caminho intercultural do saber, a ser aberto, de mentalidade científica, mas não cientificista. Este pensamento plural é necessário à educação decolonial. Esta requer, sem sombra de dúvida, fundamentação que possa contribuir para o cumprimento da justiça histórica e cognitiva, por meio da inclusão dos povos e culturas silenciadas e oprimidas pelos diversos processos de violência colonial e neocolonial. Muitos saberes e línguas indígenas foram assassinados, outros inferiorizados, desperdiçando-se, assim, riquezas de conhecimento que contribuem para o alargamento dos horizontes humanos, em diferentes aspectos.

A coteorização é importante para as línguas indígenas em suas funções cultural e educativa, mas também na composição do bilinguismo intercultural. Sem isso, as línguas e saberes indígenas ficarão sempre à margem do processo educativo. Àquelas tem na sua base a pedagogia holística, não disciplinar, e de consideração com à vida, saúde, espiritualidade, arte, cultura e valores humanos. Nesse sentido, é ilógico pensar a educação escolar sem as línguas indígenas, e sem o bilinguismo intercultural.

\section{1 Ênfase nas línguas indígenas e no bilinguismo epistêmico}

A atenção especial dada às línguas indígenas no projeto objeto deste artigo deve-se a duas razões: (1) a colonização histórica da educação escolar indígena que se deu, em primeiro 
lugar, pela língua portuguesa, e depois pelo bilinguismo de transição ou civilização; (2) o impacto dos usos das línguas indígenas no Curso de Educação Intercultural e, ao mesmo tempo, nas comunidades indígenas e nas suas escolas. Das pesquisas surgiram algumas indagações: Como as línguas e os saberes indígenas estão sendo incluídos na escola? Qual é a entrada das línguas e dos saberes na universidade? Como esses conhecimentos estão sendo legitimados na UFG?

Com relação à inclusão dos saberes indígenas na universidade, Brand (2001) problematiza a questão, destacando o fato de que não se trata apenas da inclusão dos acadêmicos indígenas na instituição, especialmente, em nossas lógicas de produção e reprodução do saber, mas de abrir espaços de diálogo em que suas linguagens e seus processos de produção de saber sejam igualmente legitimados nas Instituições de Ensino Superior. Em minha opinião, esse é um desafio gigantesco se considerarmos que a perspectiva predominante do processo de admissão dos indígenas na universidade ocorre ainda pela assimilação ao sistema universitário hegemônico e não pela equidade, ou seja, pelo reconhecimento da diversidade epistêmica e linguística. Segundo Lander (2000), os saberes que são transmitidos na universidade não produziram, de fato, uma ruptura com o imaginário colonial. O desafio é, portanto, trazer o direito das diferentes formas de conhecimento a uma existência sem marginalização e assimilação cultural.

Segundo Crystal (2005), quando uma cultura assimila a outra, a dominada passa por três grandes estágios: primeiro, há uma grande pressão sobre a população para que use a língua dominante; segundo, há um período de bilinguismo emergente, em que as pessoas se expressam com fluência na língua dominante, mas ainda fazem uso da antiga; por fim, os jovens adquirem maior domínio da língua nova e não encontram necessidade de usar a antiga. Essa realidade preocupa, e muito, os pesquisadores indígenas. Muitos deles afirmam que os jovens não estão aprendendo os usos mais especializados de suas línguas. Seus usos estão ficando restritos aos espaços do cotidiano. É importante considerar que os espaços do saber são também espaços do educar os seres humanos para que os mesmos possam assumir papeis sociais que se relacionam à coletividade.

Nos estudos com povos indígenas, esta autora observa que a língua do cotidiano é mais vulnerável. Sua vitalidade vem da conexão com os espaços de usos especializados, sagrados e do segredo. Sem esses, a língua do dia a dia perde força, e seus falantes "aceitam" gradativamente a colonização linguística. Fortalecer os espaços de usos mais especializados de suas línguas vem sendo um grande investimento dos intelectuais indígenas. É nesses 
lugares que circulam as epistemologias: artesanais, espirituais, musicais, ecológicas etc. Esses lugares estão habitados pelas vozes ancestrais, dos sábios, dos artesãos, artesãs, sábias.

Daí ser relevante um estudo dos lugares epistêmicos: ativos, inativos, em retomadas, e em atualização. Esse estudo é muito importante na adoção de políticas de vitalidade, retomada e revitalização de línguas. A política de vitalidade contextualiza-se em um movimento de retomada de saberes, já a de revitalização, vincula-se, além da retomada, à reconstrução de espaços epistêmicos ancestrais. Nestes processos, os arquitetos são os aprendizes e os ensinadores, pois em muitas comunidades, os saberes indígenas estão apenas na memória de alguns lembradores e de algumas lembradoras. Assim, os guardadores e as guardadoras precisam participar do movimento de retomada, se assim desejarem. Nesse caso, as gerações mais jovens não falam mais a língua cultural. Em algumas situações, há, ainda, os entendedores. Nesta realidade sociolinguística, o português é uma língua mediadora na contextualização cultural de ensino da língua indígena, seja no contexto de sala de aula, ou em outros espaços enunciativos. Essa ação pedagógica não se faz por meio de metodologias de línguas estrangeiras ou de segunda língua. Trata-se de uma língua materna ancestral e, como tal, exige-se considerar sua cosmologia, ecologia, afetividade, interatividade e os fazeres da vida comunitária.

Na retomada da língua deve-se considerar que a composição de cada palavra e de cada enunciado engloba sempre os lugares da enunciação e a intenção dos locutores. Além disso, provoca nos interlocutores envolvidos atitudes de respostas, visto que antes do início de um enunciado, há os enunciados anteriores; depois de seu fim, há os enunciados respostas. Daí ser importante criar atividades de movimentação enunciativa: brincadeiras, jogos, brinquedos, contar histórias etc. Essa rede enunciativa é muito importante porque ela possibilita, também, que os enunciados velhos se incorporem aos novos, propiciando, assim, a retomada de palavras, discursos e conhecimentos, como também as oportunidades para os anciãos/anciãs, sábios/sábias ensinarem aos jovens os conhecimentos milenares que, muitas vezes, pode ser a confecção de uma peça de artesanato. Isto colocará o/a aprendiz em contato com a língua de modo contextualizado e na feitura de conhecimentos.

A língua indígena vem para as pessoas (1) no fazer cultural, (2) com o sentimento da força ancestral, e na (3) interação com a natureza. Essas três ideias devem ser consideradas na organização de atividades de retomada cultural da língua, em quaisquer contextos, inclusive na escola. Nesse processo, é preciso sentir a língua, para depois fala-la, e conviver com ela. Habudja Karajá (2017. P.48), afirma “[...]viver com a língua materna é viver com os espíritos 
dos nossos ancestrais". Para Mahuwederu Karajá (2010.P.30) "não existe saber Iny sem a natureza". Fabiola Tapirapé (2010.p.40) também afirma: "se a natureza acabar, também acaba nossos conhecimentos”. Portanto, o trabalho com a língua em situação de vitalidade, retomada, ou até mesmo de reconstrução cultural, necessita de uma conjugação de saberes, esforços e ideias, incluindo a articulação entre conhecimentos de diferentes matrizes epistêmicas. Ou seja, todas as atividades criadas devem gerar aprendizagens coletivas e integração possível entre escola e os demais espaços educativos, partilhando experiências, sucesso, e muita motivação.

Nesse movimento é necessário considerar que em alguns casos precisam (1) criar oficinas para a reconstrução de espaços artesanais, artísticos, musicais etc.; em outros, são necessários apenas (2) ativar os espaços adormecidos. Em qualquer uma dessas situações, a retomada de uma língua significa sempre a retomada de saberes, lugares, modos de vida, leitura de mundo, de pensar e de fazer conhecimento. Nesse sentido, é preciso pensar que a língua não é um fenômeno deslocado ou produzido isoladamente da vida do falante. Segundo Pimentel da Silva (2009), cada pedaço de língua é, na realidade, um pedaço do mundo que a constitui, que aglutina um imaginário ancestral que lhe atribui significação. Para Mignolo, (2003, p. 633), "[...] as línguas não são apenas fenômenos 'culturais' em que as pessoas encontram a sua 'identidade'; elas também são o lugar onde se inscreve o conhecimento. E, dado que as línguas não são algo que os seres humanos têm, mas algo de que os seres humanos são [...]".

Portanto, é preciso deixar brotar os modos de aprender essa língua ancestral. A partir dessa observação, é possível criar metodologias para outros contextos de sua aprendizagem. Aprender uma língua ancestral depois da língua portuguesa, por exemplo, exige muita determinação do interessado/a. Isso significa romper com as barreiras que afastou essa língua da comunidade, da família, das pessoas. A volta dessa língua ao convívio cultural e ao seio da família, nas interações cotidianas, na feitura de conhecimento, representa uma grande conquista para a comunidade. É, de fato, um processo de descolonização, no sentido mais profundo que, no entendimento de Paulo Freire, significa expulsar essa sombra pela conscientização, esta é uma das fundamentais tarefas de uma educação realmente libertadora e, por isso, respeitadora do homem e da mulher como pessoa. Esse é o chamado especial para a educação intercultural problematizadora que, ao ser oposta à educação bancária, coloca em pauta um projeto de esperança, não sem luta, mas mantendo, em seu conjunto, o compromisso com uma pedagogia do oprimido, da autonomia, da tolerância, dos sonhos possíveis, para me 
referir a algumas concepções freiriana. Insiro, nessa contextualização, a pedagogia da retomada, defendida por Pimentel da Silva (2017).

A educação problematizadora nos mostra o quanto é possível reverter a situação das línguas indígenas brasileiras. Para isso, precisamos pensar como Freire (2004) pensa a educação, como um ato de amor, por isso, um ato de coragem. Percebe-se esse investimento de amor e de problematização nos docentes e discentes do curso de Educação Intercultural, tanto pelos pesquisadores/as indígenas quanto pelos não indígenas. Grande parte dessa atitude é provocada pelo próprio curso que, ao se fundamentar nos princípios da interculturalidade e da transdisciplinaridade, exige de todos e todas docentes posturas pedagógicas contrárias à exclusão dos saberes e das línguas indígenas da sala de aula e em qualquer outra atividade acadêmica. A efetivação política dessa proposta pedagógica realiza-se por meio de temas contextuais. Estes favorecem, além da articulação de saberes, o esticamento do conhecer, fenômeno que se realiza com a coaprendizagem. Esta atitude é entendida por Morin (2010) como possibilidade de transgressão das fronteiras impostas pelas disciplinas acadêmicas. Tal transgressão, no meu compreender, além de quebrar as barreiras disciplinares, favorece a visibilidade de outros saberes que não fazem parte das matrizes epistêmicas ocidentais.

Conhecer e compreender que a transdisciplinaridade é uma proposta de superação do ensino fragmentado e desarticulado da dinâmica da vida, é fundamental na organização de práticas pedagógicas de articulações de saberes, modos de pensar, conhecer e problematizar a realidade, revelando as diferentes dinâmicas da vida. Seguindo essas pistas, percebe-se o tema contextual, seja ele intracultural, intercultural, ou transcultural, sempre como uma composição de conhecimentos complexos. Nessa proposta pedagógica, as línguas indígenas, assim como a língua portuguesa, são vistas como línguas de conhecimento, sem assimetria, para estabelecer diálogos epistêmicos. Essa concepção gerou o conceito de bilinguismo epistêmico que, de acordo com Pimentel da Silva (2015), diz respeito às línguas, mas também aos conhecimentos que elas sediam, e que elas, por meio de seus falantes, favorecem a circulação dos conhecimentos na escola e na comunidade.

A noção de bilinguismo epistêmico é um reconhecimento das línguas em articulação epistêmicas e a serviço da coapendizagem em práticas pedagógicas intraculturais e interculturais. Nessa realidade, o bilinguismo se caracteriza como um encontro de conhecimentos de várias origens culturais. Essa ideia contribui com a entrada dos saberes indígenas na escola, não pelos cânones hegemônicos da cientificidade tradicional quando, na maioria das vezes, são apelidados, mas pela liberdade de se produzir outras realidades 
educativas. Isso combina com o pensamento de Freire (1967), ao afirmar que não é possível pensar uma teoria pedagógica que não esteja atrelada à compreensão que se tem do mundo. Santos e Almeida Filho (2008, p. 10) chamam a atenção para a "[...] necessidade de abertura da instituição acadêmica para a sociedade que a abriga e sustenta, indo além do Estado e do mercado, incluindo família e movimentos sociais".

O pensamento complexo significa saber da incompletude do conhecimento, pensamento nada simples, pelo contrário, consiste em uma proposta de desafios. Entender isso é ponto importante para repudiar as práticas pedagógicas que mutilam saberes, que excluem, das pessoas, saberes necessários às suas vidas. Pensar assim é buscar novas possibilidades teóricas, ou melhor, coteóricas, de como expurgar os processos de dominação cognitiva instaurados a partir da colonização europeia, no continente latino-americano. Essa colonização dizimou muitos povos indígenas e, consequentemente, muitos saberes e línguas. Os saberes e línguas dos sobreviventes continuam sendo ameaçados, discriminados, violentados, apagados. Apesar desse triste quadro, hoje há muitos movimentos parceiros dos indígenas, seguindo outra direção, a do entendimento amoroso e respeitoso com relação à diversidade cultural humana do mundo.

Parte desse entendimento vem por meio de uma educação intercultural que exige parcerias, pactos, negociações, trocas, mediações, até mesmo conflitos. A mudança do nosso olhar para o mundo, para as pessoas, para a cultura, comunidades e povos, pode contribuir para diminuir o preconceito que destrói vidas, despreza saberes e ignora muitas línguas faladas no mundo. A exemplo dessa realidade pode-se citar a destruição de muitas formas de saber e de dizer, fato que levou à morte muitos idiomas indígenas brasileiros, mais de $85 \%$ deles desapareceram. Conforme Pimentel da Silva (2006), atualmente muitos estão agonizantes e todos, sem exceção, encontram-se ameaçados de extinção, tanto os falados por populações pequenas, como os Avá-Canoeiro, em Goiás, quanto os falados em comunidades maiores, como os Macuxi, em Roraima. A autora aponta, ainda, a luta dos Karajá de Goiás na atualização cultural para que as gerações novas tenham acesso aos seus saberes de tradição milenar.

Problematizar tal realidade serve para contextualizar os processos educacionais neocolonizadores que continuam surdos e cegos às demandas colocadas pela educação intercultural crítica. Esses processos fixam os sujeitos, em formação, em um terreno de manutenção das hierarquias já estabelecidas pela colonialidade do saber e do ser, como apresenta Mignolo (2003). Durante minha pesquisa, procurei cartografar o que subverte a 
cultura como um ato de existir político, e de desejo de reverter o ato que provocou a morte de muito saberes e línguas. Busquei entender o que foge aos mecanismos de controle, o que escapa e cria fluxos de resistências.

\section{Reflexões sobre os impactos das línguas indígenas na Educação Intercultural}

Feitas essas considerações, retomo os resultados das pesquisas do projeto em relevo, colocando em destaque as políticas linguísticas que estão impactando o curso de Educação Intercultural e as escolas indígenas. Chamo a atenção mais uma vez para os usos das línguas indígenas nos temas contextuais, sejam eles intraculturais, quando são reivindicadas as línguas indígenas, ou interculturais, que se compõem pelo bilinguismo epistêmico. Essas propostas estão contribuindo com a sobrevivência das línguas indígenas e com a conscientização da necessidade urgente de se mantê-las em suas dimensões culturais e de criar-lhes novos status em relações interculturais. Nesses diálogos, deve-se levar em conta que uma das características das línguas indígenas é que nelas tudo toma um valor coletivo. Talvez seja por isso que ideias como retomar, esticar, articular ganharam valor no debate intercultural entre estudantes e professores/as indígenas.

Esse cuidado diz respeito também a uma política que ressalta a informação dada pela Unesco (Organização das Nações Unidas para a Educação, a Ciência e a Cultura) de que atualmente existem cerca de 6 a 7 mil línguas no mundo. Aproximadamente 97\% da população mundial fala somente $4 \%$ dessas línguas e somente $3 \%$ das pessoas do mundo falam $96 \%$ de todas as línguas existentes. A grande maioria desses idiomas falados, sobretudo por povos indígenas, continuará a desaparecer em ritmo alarmante. Sem a medida adequada para tratar dessa questão, mais línguas irão se perder, e a consequente perda da história, das tradições e da memória associadas a elas provocará uma considerável redução da rica diversidade linguística em todo o mundo. Por essa razão, perderemos também constelações de saberes existentes nos universos indígenas. Exponho essa realidade triste para ampliar a responsabilidade das licenciaturas interculturais que formam professores e professoras indígenas para atuarem em suas escolas. Medidas como as tomadas pelo curso de Educação Intercultural da UFG são iniciativas que podem afastar essas línguas do perigo de extinção se todos as entenderem não apenas como uma área de estudo de linguistas, mas como línguas de educação, de conhecimentos e de povos. 
A exigência do ensino pelo tema contextual é outro fator que tem provocado os intelectuais indígenas. Todo tema contextual exige pesquisa, que pode ser no campo da intraculturalidade como da interculturalidade, mas em qualquer uma das situações, as línguas estão sempre presentes na sua composição epistêmica.

As funções do letramento em línguas indígenas também foram observadas nas pesquisas. Segundo Pimentel da Silva (2016) já se pode pensar nas seguintes funções para se escrever em línguas indígenas: (1) acordar os conhecimentos adormecidos; (2) vitalizar os espaços culturais; (3) documentar saberes; (4) fortalecer a memória; (5) incentivar a transmissão dos saberes tradicionais de uma geração a outra; (6) trazer lembranças dos conhecimentos ancestrais; (7) gerar motivo de conversas entre gerações e na mesma geração; (8) guardar conhecimentos; (9) atualizar a cultura; (10) fortalecer a escola e vinculá-la a outros espaços educativos das comunidades; (11) fortalecer a educação própria dos indígenas; (12) inovar a língua; (13) prestigiar as epistemologias indígenas; (14) divulgar conhecimentos; (15) retomar saberes; (16) criar novos conhecimentos, novas palavras etc.

Como podemos perceber, os motivos para se escrever em línguas indígenas são bem diferentes das razões pelas quais se escreve em língua portuguesa. Nas línguas indígenas a escrita, além de estar coladinha na oralidade, visa à retomada de saberes milenares, o diálogo geracional e ancestral. Isso aumenta as potencialidades de seus usos.

Todas as questões levantadas neste texto destacam a seriedade no trato das línguas indígenas nas dimensões culturais, interculturais, bilíngues, escolares, na produção de conhecimentos, nas práticas pedagógicas, nas pesquisas e nas políticas linguísticas. Colocar essas reflexões em evidência tem por objetivo ressaltar a importância do projeto Impactos dos Usos das Línguas Indígenas na Formação de Professores Indígenas no Curso de Licenciatura Intercultural de Formação Superior de Professores Indígenas, financiado pelo Programa Observatório da Educação da Capes. É um projeto que contribuiu com a publicação de vários livros didáticos, em línguas indígenas, fundamentados no paradigma da retomada.

São livros com temáticas diversas, relacionadas à alfabetização pelos conhecimentos indígenas. São livros que formam pesquisadores indígenas, promovem a valorização de suas línguas e muita articulação de saberes que ressaltam, com prazer e descoberta, o paradigma do esticar saberes e do conhecer em diferentes espaços e realidade. São livros de documentação de saberes especializados, que promoveram encontros entre professores/professoras pesquisadores/pesquisadoras com sábios e sábias. São livros que permitiram mapear os 
lugares do saber ancestral. Nasceram desses livros conhecimentos interculturais. Os livros de histórias agitaram memórias, lembranças, e o interior humano.

Tal pensamento nos convida a refletir sobre a emergência da construção de bases coteóricas, uma visão que se baseia na articulação de saberes e que pode oferecer aos projetos de retomada de línguas indígenas, principalmente em comunidades que vivem por forças de opressão, realidades que vão desde o bilinguismo receptivo/responsivo, ao de conhecimento de poucas palavras que, ainda, residem no campo das lembranças. Muitas dessas situações foram promovidas pelo forçamento de um bilinguismo unilateral, legitimador e perpetuador preconceitos e desconhecimento da diversidade humana. Uma percepção que jamais deve ser aceita pela educação intercultural, que deve pautar-se pelo bilinguismo intercultural, entendido não apenas como um fenômeno linguístico, mas, e principalmente, como uma atitude política.

\section{Considerações em estudo}

A pesquisa é uma força relevante no combate às injustiças epistêmicas indígenas. Exemplifico essa realidade citando o feito de Itxala, que retomou o Hetohoky̆, um ritual de iniciação masculina que há mais de 40 anos não era mais realizado na aldeia. Nenhum professor da escola conhecia a produção desse ritual. O Hetohoky̆ é cheio de beleza e fartura epistêmica. A retomada do ritual deu-se graças aos pesquisadores Karajá e ao apoio dos sabedores, guardadores desse saber. É um ritual que envolve toda a comunidade e exige muito conhecimento estético, espiritual, musical, danças, religiosidade, e práticas educativas.

Nomear as coisas do mundo em conhecimento pode ajudar a torná-las mais conhecidas. Pode representar, ainda, um enriquecimento sociolinguístico para a língua mãe. Este foi o objetivo do José Kumrizdazê Xerente que, em seu trabalho, entrevistou jovens, estudantes do ensino médio, que consideram ser de grande valor o estudo para os Xerente. Os entrevistados explicaram, ainda, como os antepassados nomeavam coisas, objetos, animais, peixes, árvores etc. Essas realidades eram nomeadas pela forma, tamanho, função, cor, posição e pela sua espécie etc. Exemplo: Kritozapdo é bola, sendo Krito leite de mangaba (borracha) e Zapdo significa redonda. Os idosos entrevistados também apoiaram a pesquisa. O senhor João Simrãmi Xerente, cacique da Aldeia Cabeceira Verde, afirmou que falta aos estudantes este tipo de pesquisa. Ele afirmou, ainda, "esse trabalho é muito importante para 
nós porque as crianças vão aprender a ler e escrever nossa língua e, assim, não vão esquecêla".

Além do que já foi dito, percebo em cada pesquisa o nascimento de bases epistêmicas que emergem dos espaços culturais, e também na inauguração de marcos epistêmicos interculturais, tornando visíveis outras lógicas e formas de pensar e construir conhecimentos diferentes da lógica eurocêntrica e dominante. Essas bases podem contribuir para a libertação das escolas indígenas e para educar as escolas não indígenas, na medida em que estas forem envolvidas em eventos que estimulem o pensar e o agir intercultural.

São orientações que precisam consistir em decisão política, com fortes repercussões pedagógicas, ou seja, trata-se de ampliar o foco dos currículos, questionar seu caráter eurocêntrico e favorecer o reconhecimento da diferença. Isso significa um pensamento político totalmente desafiador, mas um convite para aprendermos juntos/as e em solidariedade verdadeira. A diversidade, representada por relações interculturais plurilíngues, quando os povos reivindicam espaços nos quais podem dizer sua própria palavra - para usar uma expressão de Paulo Freire -, coloca em crise, segundo vários estudiosos, o modelo de uma epistemologia de racionalidade única. Ou seja, o que foi dado como certo na Modernidade, a saber, a existência de uma forma por excelência de conhecer, de um meio incontestavelmente mais válido para produzir saberes confiáveis, já não se sustenta mais.

\section{Referências}

BRAND, Antonio. Educação escolar indígena: o desafio da interculturalidade e da equidade. Série-Estudos, Campo Grande, MS, n. 12, p. 35-43, jul./dez. 2001.

CRYSTAL, David. A revolução da linguagem. Tradução de Ricardo Quintana. Rio de Janeiro: Jorge Zahar Editor, 2005.

FREIRE, Paulo. Educação como prática da liberdade. Rio de Janeiro: Paz e Terra, 1967. Política e educação: ensaios. $5^{\text {a }}$ ed. São Paulo: Cortez, 2001.

KARAJÁ, Habudja. Trabalho docente e prática pedagógica inovadora. In: HERBETTA, Alexandre(org.). Novas práticas pedagógicas. Goiânia: Editora Universitária, 2018.

KARAJÁ, Teijolori. Iny-ki Ijasò riòrarunyre-my ijyy. Articulando e Construindo Saberes. v. 3, n.1, 2018, p.14-33.

KARAJÁ, Mahuwederu. Relatório de Estágio do Curso de Educação Intercultural. Goiânia: Núcleo Takinahakỹ de Formação Superior Indígena/UFG, 2010. 
MIGNOLO, Walter. Os esplendores e as misérias da "ciência": colonialidade, geopolítica do conhecimento e pluri-versalidade epistêmica. In: SANTOS, Boaventura de Sousa (org.). Conhecimento prudente para uma vida decente: um discurso sobre as ciências revisitado. Porto: Edições Afrontamento, 2003.

MORIN, Edgar. A cabeça bem-feita. Rio de Janeiro: Bertrand Brasil, 2003. Introdução ao pensamento complexo. Porto Alegre: Sulina, 2005. Ciência com consciência. 13ª ed. Rio de Janeiro: Bertrand Brasil, 2010.

PIMENTEL DA SILVA, Maria do Socorro. As línguas indígenas na escola: da desvalorização à revitalização. Signótica, v. 18, n. 2, jul/dez, 2006, p. 381-395. Reflexões sociolinguísticas sobre línguas indígenas ameaçadas. Goiânia: Ed. da UCG, 2009. 2015 Impactos da educação na vitalidade do patrimônio epistêmico iny. Goiânia: Kelps, Pedagogia da retomada: descolonização do saber. Articulando e Construindo Saberes. v. 2, n.1, 2017, p. 203-215.

Possíveis caminhos para a autonomia da educação escolar indígena. In:

NAZÁRIO, Maria de Lurdes; DUNCK-CINTRA, Ema Marta (orgs.). Diversidade cultural indígena brasileira e reflexões no contexto da educação básica. Goiânia: Espaço Acadêmico, 2016.

SANTOS, Boaventura de Sousa; ALMEIDA FILHO, N. (Org.). A Universidade no século XXI: por uma universidade nova. Coimbra: Almedina, 2008.

TAPIRAPÉ, Fabíola. Relatório de Estágio do Curso de Educação Intercultural. Goiânia: Núcleo Takinahakỹ de Formação Superior Indígena/UFG, 2010.

Zemelman, H. Voluntad de conocer. El sujeto y su pensamiento en el paradigma crítico. México D.F.: Anthropos, 2005.

Submetido em 18 de junho de 2019.

Aceito em 08 de agosto de 2019.

Publicado em 09 de agosto de 2019. 